\title{
Comparison of Noise Level Measurement of Road Surfaces in the Czech Republic Using the Close Proximity Method
}

\author{
V. Křivánek*, K. Effenberger \\ Transport Research Centre, Brno, Czech Republic, \\ * Corresponding author: vitezslav.krivanek@cdv.cz
}

DOI: 10.2478/trans-2014-0008

\begin{abstract}
Transport Research Centre (CDV) owns a uniquely-constructed trailer in the Czech Republic which serves for road surface noise level measurement using the CPX dynamic method. It is specialised equipment which is in accordance with the ISO 11819-2 standard design used in the Czech Republic. Within the EU, the measurements using the CPX method are conducted by several, primarily research-focused, institutions. In order to determine whether CDV results are eligible for international comparisons, comparison noise level measurement using the CPX method was conducted in the Czech Republic during joint work on the CESTI project (TE01020168 - Centre for Effective and Sustainable Transport Infrastructure) between CDV and Eurovia Services s.r.o. The measurement was conducted by CDV using a specially-constructed trailer. Eurovia used a specially-modified regular road vehicle manufactured in France. Results of comparison measurements at $50 \mathrm{~km} / \mathrm{h}$ show that the noise level was systematically higher on most surfaces analysed by the Eurovia company. The average difference in 14 measurements was $0.6 \mathrm{~dB}(\mathrm{~A})$ : as far as the measurement uncertainty is concerned, the acquired results are compatible.
\end{abstract}

KEY WORDS: CPX method, road-noise measurement, comparison measurement, noise tyre/pavement.

\section{INTRODUCTION}

Transport has become an important factor influencing our lives, both in positive and negative ways (Potužníková et al., 2012). These days, noise represents one of the most frequent environmental pollution sources. In Europe, noise is becoming one of the most frequently discussed topics: it is one of the five key European road infrastructure issues related to longterm road transport (2002/49/EC, 2002) as regards its negative influence on the environment and human health.

Sources of car noise mainly include the following (Sandberg \& Ejsmont, 2002): vehicle power units (motor, radiator, transmission system, exhaust pipe), vehicle tyres (tyre rolling on road surface), vehicle aerodynamics (air flow around the vehicle), vehicle brakes, vehicle bodywork (and its "rattling"), vehicle load. At low speeds (approx. $40 \mathrm{~km} / \mathrm{h}$ for passenger vehicles and approx. $60 \mathrm{~km} / \mathrm{h}$ for freight vehicles), in vehicles equipped with combustion engines, the main source of noise is the power unit. At higher speeds, tyre noise, caused by their rolling, becomes more dominant: this concerns the speeds of up to around $200 \mathrm{~km} / \mathrm{h}$. 
At higher speeds, aerodynamic noise, caused by air flow around the vehicle, becomes dominant. Regarding the majority of main roads and speed limits, the dominant source of noise comes from the contact of tyres with road surface, which is caused by a combination of physical processes (Bernhard \& Waysona, 2005). The reduction of noise originating from the contact of tyres with the road surface is a significant measure on the part of the source (Raitanen, 2005; Ahammed \& Tihge, 2008). The monitoring and timely exchange of the wearing course of road surface can significantly contribute to long-term sustainability of transport and decrease negative impacts on the environment and health, owing to effective restrictions of excessive noise load from road transport (Morgan, 2006; Máca et al., 2012).

Practical monitoring (Paje et al., 2010; Wong et al., 2009) is frequently performed using the dynamic CPX method. The measurement using the CPX method is conducted in accordance with ISO 11819-2 (ISO/DIS 11819-2, 2012) and 11819-3 (ISO/TS 11819-3, 2012) standards at speeds from $40 \mathrm{~km} / \mathrm{h}$ (Mak et al., 2011). This method neither depends on traffic flow nor on travel on road: it can be applied anytime, provided the required meteorological conditions have been met (Ejsmont \& Mioduszewski, 2009); it also enables assessment of both short and long road segments and following segments. The basic description of the measuring process using the CPX method was given in the previous issue of ToTS (Křivánek, 2013). The CPX method is used for (Mak et al., 2012): monitoring of acoustic behaviour of road surface over several years of its usage, comparison of noise levels on individual road surface types, verification of the efficiency of low-noise road surfaces, etc. In comparison with other measurements, the CPX method is more practical, less demanding on measuring conditions, and also faster, more economical and capable of excluding partial disturbing components. The disadvantages of the CPX method are that it only records the tyre/surface noise, i.e. it does not account for effects of the surroundings on noise reduction, and the fact that it requires a minimum length of a measured road segment (starting and braking distance).

Since 2011 CDV has conducted noise level monitoring of individual surface types using the CPX method (Křivánek et al., 2012) on selected road segments in the Czech Republic, with strict observation of newly designed standards ISO 11819-2 and 11819-3, in order to secure long-term repeatability and comparability of results with foreign data in a long-term time horizon, so that the results can be objectively compared (Krrivánek et al., 2013). There was an opportunity for basic evaluation of results within the CESTI research project: it was possible to implement simultaneous independent measuring using another device than the specialised CDV trailer.

\section{CPX MEASURING DEVICE PARAMETRES}

CDV conducted measurement of noise levels from tyre/road surface contact using the CPX method in accordance with the ISO standard (ISO/DIS, 2012), with a specialized trailer towed by a specialized passenger car, as shown in Figure 1. The tyre used was Uniroyal Tigerpaw 225/60-R16 from the USA, designated as SRTT (Standard Reference Test Tyre). It is one of two tyres recommended in the proposed ISO 11819-3 standard (ISO/TS 11819-3, 2012).

Eurovia conducted noise measurement using the CPX method in accordance with the French national standard (LCP No. 63, 2008) with a standard passenger car, which was customised in order to meet the measurement requirements, as shown in Figure 2. This is similar to the proposed ISO 11819-2 standard (ISO/DIS 11819-2, 2012): however, the national standard (LCP No. 63, 2008) does not indicate a tyre type to be used, it only lists specific requirements on them (such as the depth of tyre tread, which must be higher than $2 / 3$ of the original value). During their measurement, Eurovia used the Michelin 195/60/R15 tyre. 


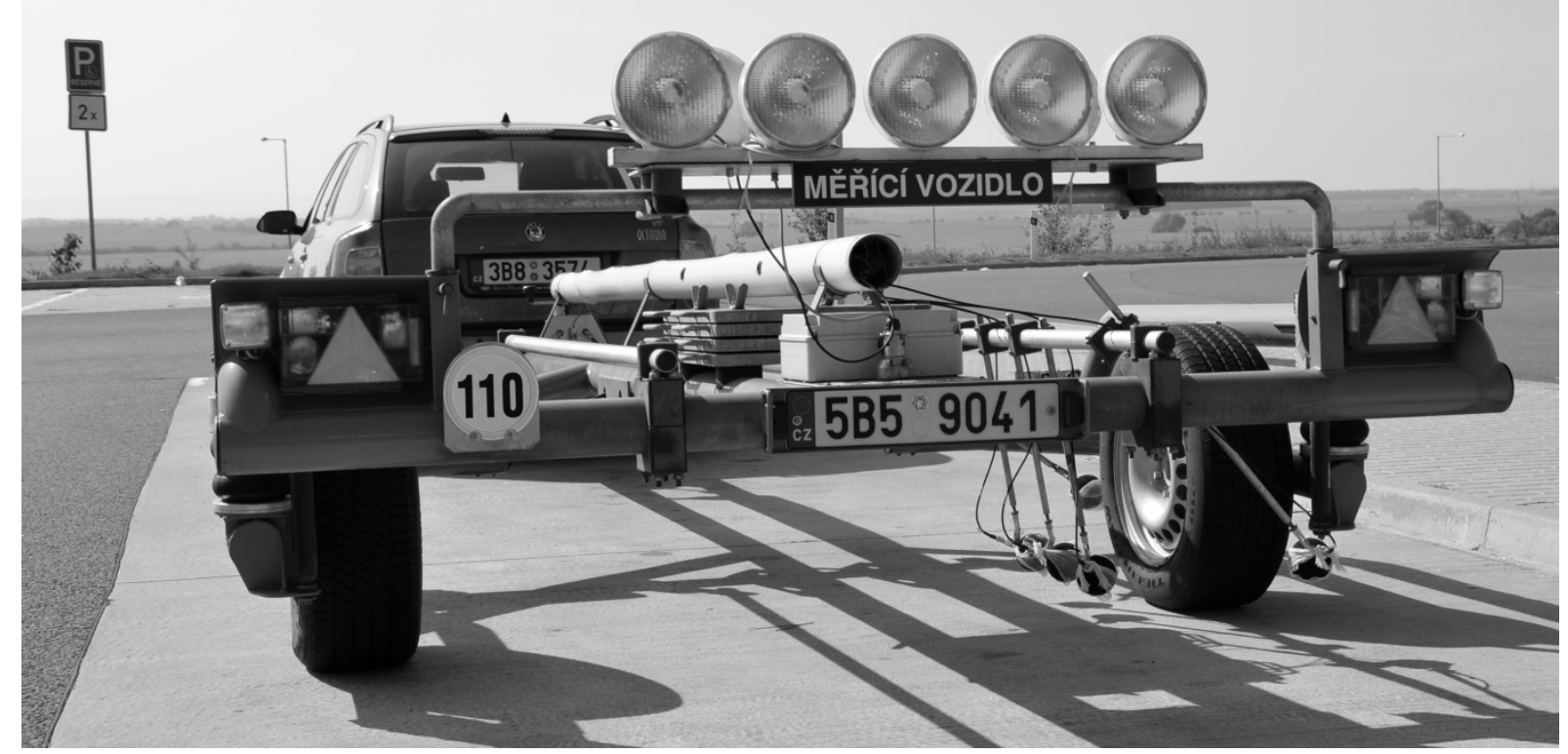

Figure 1: CDV measurement vehicle, CPX method.

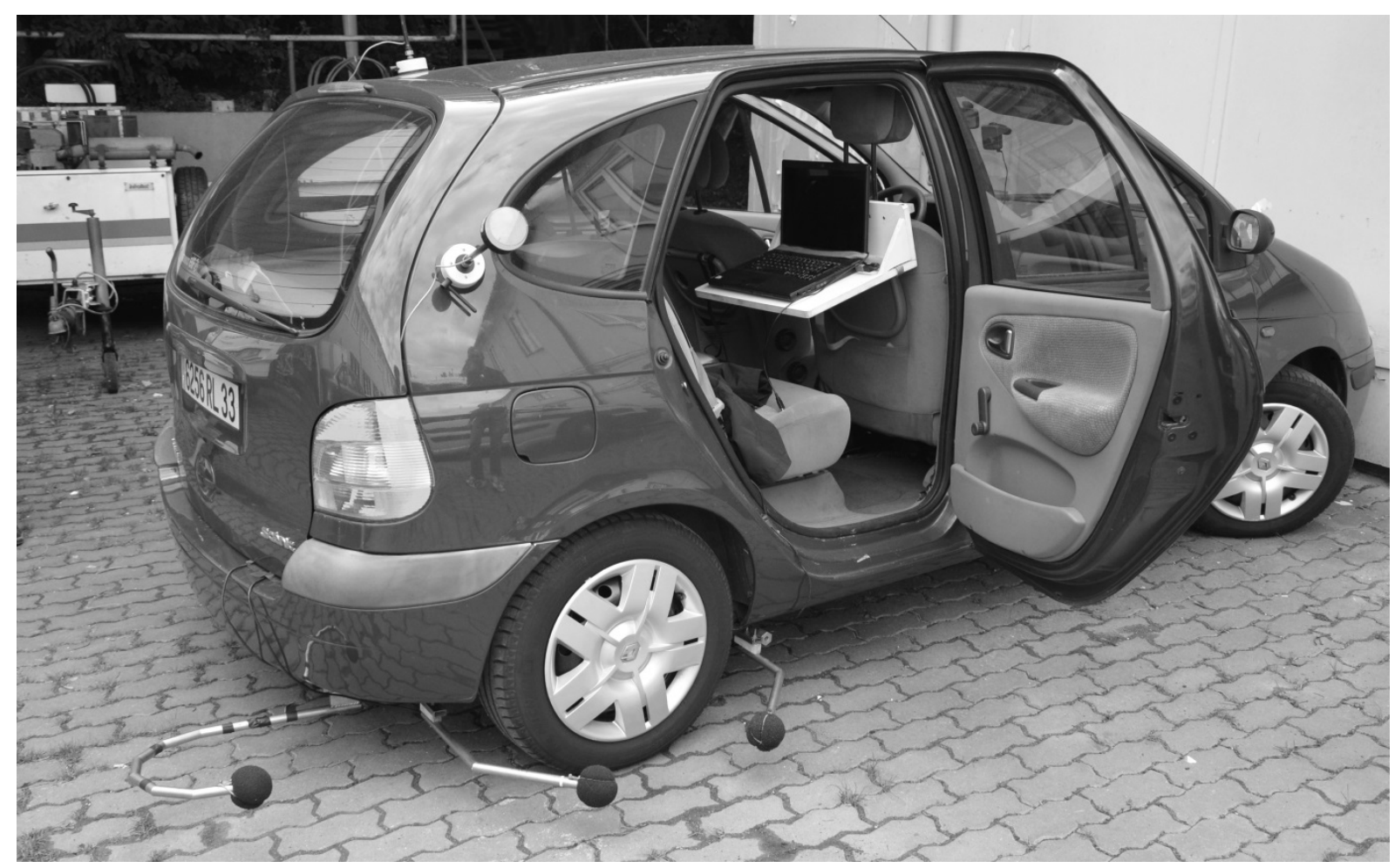

Figure 2: Eurovia measurement vehicle, CPX method.

Detailed view of tyre tread on the tyres used is shown in Figure 3. The influence of the chosen measurement tyre represents the biggest uncertainty of noise levels from tyre/road surface contact (Morgan et al., 2009) - each device was equipped with a different measurement tyre, it can therefore be expected that differences between the measured values were caused by this fact. 

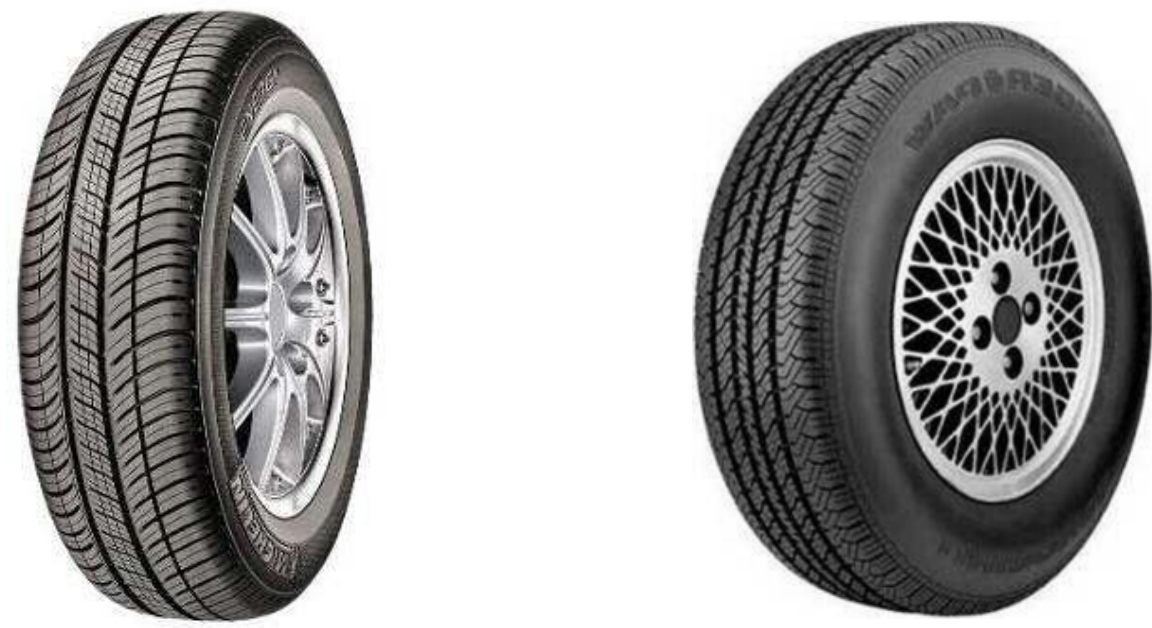

Figure 3: Michelin Energy 195/65-R15 Uniroyal Tigerpaw 225/60-R16.

Comparison of individual partial parameters of the respective complex setups for CPX measurement is given in Table 1 .

Table 1: Parameters of CPX measurement devices.

\begin{tabular}{|c|c|c|}
\hline Parameter & $\mathrm{CDV}$ & Eurovia \\
\hline Standard & $\begin{array}{l}\text { ISO/CD 11819-2 Acoustics - } \\
\text { Measurement of the influence of } \\
\text { road surfaces on traffic noise - Part } \\
\text { 2. (ICS } 17.140 .30 \text { from } 20 \\
\text { December 2012) }\end{array}$ & $\begin{array}{l}\text { “Mesure en continu du bruit de } \\
\text { contact pneumatique/chaussée, } \\
\text { Méthode d’essai n63 LCP” from } \\
2008\end{array}$ \\
\hline Measurement & $\begin{array}{l}\text { On a measurement trailer, towed by } \\
\text { Škoda Octavia, engine } 2.0\end{array}$ & $\begin{array}{l}\text { Directly on the car - Renault } \\
\text { Scénic, engine } 1.9 \mathrm{TDi}\end{array}$ \\
\hline Tyre & Uniroyal Tigerpaw 225/60-R16 & Michelin Energy E3A195/60/R15 \\
\hline Tyre pressure & $200 \mathrm{kPa}$ & $220 \mathrm{kPa}$ \\
\hline Tyre mileage & $12000 \mathrm{~km}$ & $125000 \mathrm{~km}$ \\
\hline $\begin{array}{c}\text { Number of } \\
\text { microphones }\end{array}$ & 5 & 3 \\
\hline $\begin{array}{l}\text { Microphone } \\
\text { type }\end{array}$ & Brüel \& Kjær, type 4189 & Brüel \& Kjær, type 4189 \\
\hline $\begin{array}{c}\text { Speed } \\
\text { measurement }\end{array}$ & GPS & Independent wheel tachometer \\
\hline $\begin{array}{l}\text { Temperature } \\
\text { measurement }\end{array}$ & Infrared sensor & Infrared sensor \\
\hline $\begin{array}{c}\text { Measurement } \\
\text { uncertainty }\end{array}$ & $+/-1,0 \mathrm{~dB}(\mathrm{~A})$ & $+/-1,4 \mathrm{~dB}(\mathrm{~A})$ \\
\hline
\end{tabular}

\section{MEASURED SURFACE NOISE LEVEL VALUES USING THE cpx METHOD}

The compared result of measurement is represented by the equivalent level of acoustic pressure $\mathrm{A}$ of the tyre/road surface contact. The acquired data underwent post-processing, 
which eliminated possible disturbing influences. Furthermore, necessary corrections were performed using the acquired actual speed values, air temperatures and road surface temperatures. Table 2 shows corrected equivalent acoustic pressure A levels at reference speed $50 \mathrm{~km} / \mathrm{h}$ and reference temperature $20^{\circ} \mathrm{C}$.

Table 2: Selected measurement results, CPX method.

\begin{tabular}{|c|c|c|c|}
\hline Measured segment & $\begin{array}{l}\text { Surface } \\
\text { type }\end{array}$ & $\begin{array}{c}\text { Tyre Uniroyal } \\
\text { Tigerpaw } \\
\text { 225/60-R16, } \\
\text { corrected } L_{\text {Aeq }} \\
\text { to ref. values } \\
\text { [dB(A)] }\end{array}$ & $\begin{array}{c}\text { Tyre Michelin } \\
\text { Energy } \\
\text { 195/60/R15, } \\
\text { corrected } L_{\text {Aeq }} \\
\text { to ref. values } \\
\text { [dB(A)] }\end{array}$ \\
\hline Experimental measurement segment 1 & Viaphone & $89,2 \pm 1,0$ & $91,0 \pm 1,4$ \\
\hline Experimental measurement segment 2 & Viaphone & $89,2 \pm 1,0$ & $89,9 \pm 1,4$ \\
\hline Experimental measurement segment 3 & Viaphone & $89,3 \pm 1,0$ & $90,5 \pm 1,4$ \\
\hline Experimental measurement segment 4 & SMA8 LA & $90,0 \pm 1,0$ & $90,5 \pm 1,4$ \\
\hline Experimental measurement segment 5 & SMA 8 & $92,5 \pm 1,0$ & $93,2 \pm 1,4$ \\
\hline Experimental measurement segment 6 & SMA 8 & $92,5 \pm 1,0$ & $93,2 \pm 1,4$ \\
\hline Experimental measurement segment 7 & SMA 11S & $93,7 \pm 1,0$ & $94,7 \pm 1,4$ \\
\hline Experimental measurement segment 8 & SMA 11S & $93,8 \pm 1,0$ & $94,9 \pm 1,4$ \\
\hline Experimental measurement segment 9 & $\begin{array}{c}\text { mixture } \\
\text { PA } 8\end{array}$ & $88,4 \pm 1,0$ & $88,3 \pm 1,4$ \\
\hline Experimental measurement segment 10 & $\begin{array}{l}\text { mixture } \\
\text { PA } 8\end{array}$ & $90,7 \pm 1,0$ & $90,4 \pm 1,4$ \\
\hline
\end{tabular}




\section{CONCLUSION}

In order to verify possibilities of using the results acquired from the CPX method measurement in the Czech Republic, as well as for purposes of international comparisons, using a specially-constructed CDV trailer, comparison measurements with the equipment of the Eurovia company during work on the CESTI project were conducted on selected sites in the Czech Republic. Although both measurement systems show minor differences, as demonstrated in Table 1, with the highest uncertainty originating from the use of different measurement tyres, the results are, as far as measurement uncertainties of the respective methods are concerned, comparable (see Table 2). Comparison measurement results at $50 \mathrm{~km} / \mathrm{h}$ showed that noise on a majority of surfaces is systematically higher on the Eurovia device. This systematic deviation differs according to the actual surface type, which presumably owes to varying tyre treads. In 12 out of 14 measurements, noise levels measured by Eurovia were higher. The average difference in noise levels in all measurements was $0.6 \mathrm{~dB}(\mathrm{~A})$.

The acquired results correspond with the data from foreign academic texts (Schwanen et al., 2007), which also analyse results of comparison CPX measurements: 13 segments showed higher noise levels for a similar tyre - Michelin Energy 205/65-R15, 5 segments showed the same noise levels and 4 segments showed higher noise levels for a tyre Uniroyal Tigerpaw 225/60-R16.

It can be said that the device used by CDV for monitoring noise levels of individual surface types using the CPX method, provided this monitoring is conducted in accordance with up-to-date designs of the ISO 11819-2 and 11819-3 standards, enables long-term repeatability and comparability of results with foreign data in a long-term horizon.

\section{ACKNOWLEDGEMENTS}

This paper was composed on the basis of activities funded within Ministry of Education, Youth and Sport project - Research and Development for Innovations Operation Programme No. CZ.1.05/2.1.00/03.00 and Technology Agency of the Competence Centre programme TA CR, project No. TE01020168 (Centre for Effective and Sustainable Transport Infrastructure).

\section{REFERENCES}

2002/49/EC, 2002. Directive 2002/49/EC of the European Parliament and of the Council of 25 June 2002 relating to the assessment and management of environmental noise. Off J Eur Communities. 2002; 45(L 189/12): 12-25.

Ahammed, M. A., Tihge, S. L., 2008. Quiet Pavements: A Sustainable and Environmental Friendly Choice. In Transportation - a key to a sustainable future: 2008 Annual Conference \& Exhibition of the Transportation Association of Canada, September 21-24, 2008.

Bernhard, R. J., Waysona, R. L., 2005. An Introduction to Tire/Pavament Nosie. Final Research Report Number: SQDH 2005-1. Purdue University, USA, 2005.

Ejsmont, J. A., Mioduszewski, P., 2009. Certification of vehicles used for tire/road noise evaluation by CPX method. Noise Control Engineering Journal, 57 (2), pp. 121-128. ISSN 0736-2501. 
ISO/DIS 11819-2, 2012. Acoustics - Measurement of the influence of road surfaces on traffic noise - Part 2. "Final draft of ISO/DIS 11819-2 CPX Method”, signature ICS 17.140.30.

ISO/TS 11819-3, 2012. Acoustics - Method for measuring the influence of road surfaces on traffic noise - Part 3: Reference Tyres.

Krrivánek, V. et al., 2012. Changing noise road surfaces over several years using. Progress report. Brno: Transport Research Centre (CDV). 109 p. Submitter: Technology Agency of Czech Republic. (in Czech)

Křivánek, V., 2013. Measurement of Noise from Road Surface Using Dynamic Method. Transactions on Transport Sciences, 6 (3), pp. 117-124. ISSN 1802-9876.

Křivánek, V., Pávková, A., Jedlička, J., 2013. Noise measurement of road surface by the dynamic CPX method. In ICOEST Cappadocia 2013, Nevsehi (Turkey), June 1821, 2013, pp. 198-203. ISSN 2147-3781.

LCP No. 63, 2008. Mesure en continu du bruit de contact pneumatique/chaussée, LCP No. 63.

Máca, V., Urban, J., Melichar, J., Křivánek, V., 2012. Metodika oceňování hluku z dopravy, 29 p. Prague: Centrum pro otázky životního prostředí UK. (in Czech)

Mak, K. L., Lee, S. H., Ho, K. Y., Hung, W. T., 2011. Developing instantaneous tyre/road noise profiles: A note. Transportation Research Part D, 16 (3), pp. 257-259. ISSN 0003$682 \mathrm{X}$

Mak, K. L., Hung, W. T., Lee, S. H., 2012. Exploring the impacts of road surface texture on tyre/road noise - A case study in Hong Kong. Transportation Research Part D, 17 (2), pp. 104-107. ISSN 1361-9209.

Morgan, P., 2006. Guidance Manual for the Implementation of Low-Noise Road Surfaces. SILVIA Project Report. Brussels (Belgium): FEHRL. ISSN 1362-6019.

Morgan, P., Sandberg, U., Blokland, G., 2009. The selection of new reference test tyres for use with the CPX method, to be specified in ISO/TS 11819-3. Inter noise 2009 Inovations in practical noise control, August 2009, Ottawa, Canada.

Paje, S. E., et al., 2010. Monitoring road surfaces by close proximity noise of the tire/road interaction. Journal of the Acoustical Society of America, 122 (5), pp. 2636-2641. ISSN 0001-4966.

Potužníková, D. et al., 2012. A Change in the methodology of noise assessment in protected outdoor environs of buildings as related to health risk assessment. Hygiena, 57 (4), pp. 149-153. ISSN 1802-6281. (in Czech)

Raitanen, N., 2005. Measuring of Noise and Wearing of Quiet Surfaces. Helsinki (Finland): University of Technology. ISBN 951-22-7694-1.

Sandberg, U., Ejsmont, J. A., 2002. Tyre/road Noise Reference Book. Kisa (Sweden): Informex. ISBN 91-631-2610-9.

Schwanen, W., Blokland, G., Leeuwen, M., 2007. Comparison of potential CPX-tyres Variability within AVON AV4 and SRTT tyre type, $M+P$ - Consulting Engineers. Report DWW.07.04.2. 
Wong, K. W. et al., 2009. A new methodology of measuring tyre/joint noise in Hong Kong. In 4th International Symposium on Environment Vibrations - Prediction, Monitoring, pp. 59-604.

The article was produced under the support of the project

Transport R\&D Centre (CZ.1.05/2.1.00/03.0064) 